\title{
Leo Strauss on Social and Natural Science: Two Previously Unpublished Papers
}

\author{
Edited by José A. Colen and Svetozar Minkov
}

The two papers published here for the first time were written by Leo Strauss (1899-1973) in or around 1945, when he was teaching at the New School for Social Research in New York City. One of Strauss's colleagues at the New School was Kurt Riezler (1882-1955). Riezler had earned a PhD in classics, but had an even more distinguished career as a practical politician; he had been a high-ranking cabinet member in both Imperial and Weimar Germany and a drafter of the Weimar constitution. He had wide-ranging scholarly interests, having written books on the theoretical foundations of politics, art, ancient philosophy, and the fundamental structure of social life. Because they shared an interest in the foundations of social science, he and Strauss co-taught a couple of courses in the mid-1940s (on Aristotle's De anima and Descartes's Passions of the Soul [along with Solomon Asch], and on Plato's Theaetetus [along with Alexandre Koyré]). Strauss indicated the enduring respect he had for Riezler in a eulogy he wrote for him in 1955 and republished as the concluding essay in What Is Political Philosophy? and Other Studies in 1959.

The papers presented below constitute a kind of debate. Strauss and Riezler agreed that social science in its current form is indefensible. Economists, sociologists, anthropologists, psychologists, political scientists, and historians all study human beings and the societies they form from a variety of perspectives, with different methods, and a demonstrated inability to explain how the findings of these varied disciplines can be integrated or related. Strauss and Riezler disagreed, however, about the proper response to that disarray.

In the first paper printed below Strauss maintains that the problem can be solved only by formulating a "frame of reference," that is, "a conceptual

José A. Colen, Universidade do Minho and École des Hautes Études en Sciences Sociales, Research Fellow supported by Fundação para a Ciência e Tecnologia, R. Costa Goldofim 4 r/ch 1000-104, Lisbon, Portugal (jose.colen.pt@gmail.com).

Svetozar Minkov, Associate Professor of Philosophy, Roosevelt University, 430 S. Michigan Ave., Chicago, IL 60605 (sminkov@roosevelt.edu). 
scheme that mirrors or articulates the essential structure of society as such, and therefore of every possible society. This essential structure would be defined by the purpose of society, or by the natural hierarchy of its purposes." Strauss recognizes, however, that many social scientists deny that there is or can be any such "essential" structure or "frame of reference." On the contrary, they observe that there are many different societies existing at different times and places, and that the members of these societies necessarily see things from the perspective of their own. So long as "scientists" study other societies only from the perspective of their own, Strauss counters, they will never understand other, for example, "indigenous" societies as the members of those societies understand them. Such "scientists" will not even understand their own societies, because what is distinctive about their own societies becomes clear only in comparison to others. Strauss grants that there is a fundamental difference between the "objective" understanding of a society a scientist seeks and the self-understanding of nonscientifically educated cultures. But he concludes that if we are to achieve anything that deserves to be called social science, we must attempt to combine a scientific understanding with the selfunderstandings of all the societies we study in a more comprehensive understanding that includes both.

Since the concept of "society" itself arises relatively late in the intellectual history of the West, Strauss then observes, we need to seek a more elementary formulation of the topic that applies to virtually all times and places. It can be found in the contrast between "'we here with our way,' as distinguished from 'they there with their way,'" because such a formulation meets the "two decisive conditions" of "universal applicability, and universal intelligibility." But how can we escape the limitations on our vision imposed by seeing things "our way"? Strauss observes that "our way" in the West is, in fact, the product of two radically different traditions, Greek and Hebrew. By investigating those two roots, we find that they have a common basis in a "notion of divine law, a notion that can be shown to be a necessary consequence or a more thoughtful expression of what all peoples originally mean when they speak of their way." That notion of a divine law became questionable as soon as people became sufficiently cognizant of the variety of ancestral or divine ways. From that questioning arose the ideas of nature and science; and "in the light of the ideas of nature and science the Greeks investigated the various tribes to which they had access. For these investigations they used a clear and simple scheme which is still immediately intelligible to us." Because "that scheme is historically so close to what was originally common to all peoples ... it is least likely to be based on any particular and questionable assumptions." By recovering "the frame of reference used by the classics," Strauss thus concludes, "we would recover the natural [nonarbitrary] frame of reference."

Instead of returning to the classics to find a "natural frame of reference," Riezler called for the development of a single science of man in an article he published in Social Research entitled “Some Critical Remarks on Man's 
Science of Man." ${ }^{1}$ In the second paper below, Strauss begins by summarizing the advantages of Riezler's approach or ambition. A single science of man "would be a fundamental science, if not the fundamental science. By understanding the one and indivisible phenomenon 'Man' in its completeness, by understanding how this one phenomenon offers different 'aspects' ... of different relevance and 'depth,' it would supply the many sciences which deal with the various 'aspects' of man with ... their subject matter." It would thus seem to constitute the natural "frame of reference" Strauss argued was the necessary starting point and basis of a "social science" properly so called.

Strauss objects, however, that "the demand for the one science of man is not self-evident." If it were, the history of philosophy would abound with the records of philosophers seeking such a science. In fact, "classical philosophy had no place for the one science of man: it split up the study of man among the theoretical and practical philosophy, or among logic, physics, and ethics." And as a consequence of this classical division of philosophy or science, "the splitting up of the study of man among a number of distinct disciplines is still generally taken for granted." The "same reasoning that leads to the demand for the one science of man, leads to the demand for one science of 'the whole.' ... As the one nature of man embraces body and mind, individual and society, physical and mental experience, 'one nature' embraces both human and nonhuman nature." But, Strauss explains, "this reasonable longing for unity and intelligibility cannot be fulfilled by modern natural science," which has been "utterly unable to do justice to the phenomenon 'Man,'" because it understands nature on the basis of specific assumptions that "are dictated by the requirements of a specific method rather than by the nature of things." The universal science to which Riezler's arguments point "would be akin not to modern natural science, but to the natural science of Aristotle or of Goethe." Riezler denies, however, that a comprehensive science of nature, both human and nonhuman, is possible, because he maintains that such "cosmic schemes" depend upon "the dynamic context" of human life from which they arise. "If man's views of the cosmos necessarily change in accordance with the changes of the 'dynamic context' in which he lives," Strauss objects, all we have are the views of various individuals or groups living at different times and places. We do not have a unified "science of Man"; we do not, in fact, have anything that deserves to be call "science" at all.

This unpublished debate with Riezler shows that in "On Classical Political Philosophy," an article he published in Social Research at approximately the same time (1945) and included later in What Is Political Philosophy?, Strauss was not merely trying to recapture or revive classical political philosophy. He was seeking to articulate the only nonarbitrary, universally applicable

\footnotetext{
${ }^{1}$ Kurt Riezler, “Some Critical Remarks on Man's Science of Man," Social Research 12, no. 4 (1945): 481-505.
} 
and universally intelligible basis of any social science, properly speaking, modern as well as ancient. As he states in his critique of Riezler, however, Strauss also thought the "reasonable longing for unity and intelligibility" required a "universal science of nature" that cannot be had on the basis of modern natural science and that is not now and may never be available to us. He thus indicates the reasons he later maintained that philosophy consists in a Socratic search for wisdom rather than the possession of knowledge.

Editors' note: We have transcribed handwritten portions of the papers and have standardized spelling and punctuation, italicized titles and foreign words, corrected a few minor errors, inserted a few words in brackets, and used footnotes to indicate Strauss's own changes and to provide relevant information. We are responsible for any errors. The numbers in square brackets represent the page numbers in the originals found at the Leo Strauss Archives, Box 10 (folders 10 and 9 respectively). Copyright to both texts below is retained by the estate of Leo Strauss. We thank Nathan Tarcov, Strauss's literary executor, for giving us permission to publish them, and Catherine Zuckert for helping us prepare the papers for publication in the Review of Politics.

\section{Leo Strauss Papers, Box 14, Folder 10 The frame of reference in the social sciences}

[1] Social science is an empirical science dealing with facts and their causes, and nothing but facts and their causes. Let us assume that we know what a fact is and what a cause is. Then the first difficulty arises from the circumstance that social science doesn't want to deal with all social facts, but only with relevant facts. It presupposes then criteria of relevance. The system of those criteria may be called the frame of reference. Without a frame of reference social science would have no subject matter. Without a frame of reference, no facts. The question then is, How do we get a sensible frame of reference? The best solution would be a frame of reference which is in no way arbitrary and accidental: the natural frame of reference, that is to say, a conceptual scheme that mirrors or articulates the essential structure of society as such, and therefore of every possible society. This essential structure would be defined by the purpose of society, or by the natural hierarchy of its purposes. The essential structure and the hierarchy of the purposes would guide the social scientist, they would tell him what is essential and therefore important, and what is accidental and therefore unimportant, to say nothing of the fact that it would tell him what is good and bad. The accidental would not be regarded as absolutely unimportant. It would be of crucial importance for a given group of people here and now, that is to say, for action, and therefore it deserves the most careful attention of the statesman or citizen. But from the point of view of the social scientist-who as such is not a statesman or citizen, but a teacher of statesmen or citizens; who as a scientist is a citizen 
of the world, not of any particular country - the practically important things which are accidental and ephemeral would have to be kept in their place: in a subordinate place. [2] An example: the idiosyncrasies of a dictator are terribly important for all who have to live with that dictator, but these idiosyncrasies are not the essence of dictatorship. ${ }^{2}$

Present-day social science is inclined to reject the very notion of a natural frame of reference. It is inclined to think that the notion of a natural frame of reference is based on a fundamental delusion, or on blindness to an all-important fact. The fact is called history. There cannot be a natural frame of reference if society as society doesn't have a permanent or unchangeable character or structure. But, it is argued, society changes radically. That is to say, its very structure differs from period to period or from civilization to civilization. Furthermore: there cannot be a natural frame of reference if man is not capable to raise himself above his historical situation to a realm of "essences" which is not affected by historical change. But, it is argued, human thought itself is radically historical; man doesn't think in a vacuum, human thought always belongs to a historical and dynamic context, with whose change human thought itself changes. Accordingly, there are as many frames of reference as there are historical situations. Even granting that in every historical situation the core is "man in ${ }^{3}$ society," that is to say, something which is permanent, it is impossible to grasp and to express that permanent thing in a permanently valid manner: in a manner which in principle is valid for all men and all times. Man's understanding of man and society is always bound up with a historical situation to which the individual thinker happens to belong. Or, to state it more simply, the frame of reference of the social sciences is the totality of fundamental questions we address to social phenomena. These questions depend upon the point of view, or the direction of interest, of the questioner. But the point of view or the direction of interest depends upon the social situation, that is to say, on something radically changing or historical. [3] Hence there cannot be a natural frame of reference, that is to say, a conceptual scheme which in principle is final, valid once and for all. The only scheme which is possible is a scheme belonging to our situation, our age-a scheme which is, strictly speaking, ephemeral. Our present scheme will be replaced by another one as soon as our age has ceased to be. The scheme imposed upon us by our situation, by our historical fate, has to be made explicit, it has to be clarified, it has to be liberated from the residues of earlier and obsolete ways of thinking. After this treatment, our scheme permits us to study social phenomena in a scientific manner, it allow us to study the social phenomena which are relevant from our present point of view and as they are relevant from our present point of

\footnotetext{
${ }^{2}$ Strauss had written by hand but then crossed out the following sentence: "What is essential is that in dictatorship the idiosyncrasies of a single man have a terrible effect."

3Strauss has crossed out "and."
} 
view. The scheme doesn't reflect the essential nature of society. It reflects the questions which we here and now are forced to address to social phenomena. The scheme does not correspond to the structure of the subject matter. Compared with the subject matter our scheme has the character of a construction, of an artificial model: our scheme consists of ideal types. Our scheme is then a mere tool for the articulation of social reality, it has no cognitive value in itself.

Is social science possible on the basis of such a type of frame of reference? My answer is no. For this kind of frame of reference admittedly reflects the way in which our own society understands itself in our own time. Accordingly, by using such a frame of reference we interpret societies other than our own in terms that are wholly alien to those societies. We force those societies into the Procrustean bed of our conceptual scheme. We do not understand those societies as they understand themselves. But the way in which a society understands itself is an essential element of its being, not to say that it is the very essence of each society. Hence we shall not understand those societies as what they are. And since we cannot understand our own society adequately if we do not understand societies [4] other that our own, we will not be able to understand even our own society. We have then to liberate ourselves from the frame of reference that fate has imposed upon us, so that we can understand societies other than our own as they understand themselves, and therewith, ultimately, our own society. Otherwise, by going to remote times and countries, we shall never leave our here and now, we shall remain enmeshed in a learned parochialism.

If our frame of reference essentially belongs to our historical situation it is a hindrance to our understanding of other societies. If we want to understand other societies, we have to understand them in terms of their frames of reference. After having abandoned the notion of a natural frame of reference we have now to abandon the view that any single frame of reference will do. We shall have to have a variety of frames of reference in accordance with the variety of societies. Social science has to become strictly historical or interpretative. For example, we must not impute the notion of "state" [a typically modern notion $]^{4}$ or the distinction between "state" and "society" to any society which doesn't know of it. Or the notion of "art," and the implied distinction between "art," "religion," "morality," and "science." Needless to say, this would apply to the key concept "civilization" itself. No society but western society of the 19th and 20th centuries ever understood itself as " $a$ civilization." We must open our minds to the possibility that concepts of an entirely different type would have to become our guiding notions.

But it is impossible to leave it at that, however great and deep the variety of societies, they all are societies. If the term social science is to have any meaning, it must be concerned ultimately with one self-identical object. We express this identity by speaking of societies. But the question arises

\footnotetext{
${ }^{4}$ The square brackets are Strauss's.
} 
whether the notion "society," while less dated than the notion "civilization," is not also bound up with a specific orientation. One merely has to try to translate the term "societies" as we use it into Greek to see this. We seem to penetrate to a deeper or more elementary stratum by substituting for society "we here with or way," as distinguished from "they there with their way." It would seem that this orient-[5]ation is truly universal, that is to say, it is universally understood. By making the notion "we here with or way" the key concept, we might seem to keep within the horizon, the conscious horizon, of every possible society. A notion of this kind would meet the two decisive conditions: universal applicability, and universal intelligibility.

But still, however careful and ascetic we might try to be, we cannot help adding something of our own and therewith interfering with the object of our studies. The study of societies has frequently been guided by the distinction between environment and civilization. Students have tried to understand a civilization, or the world of a people, as a product of its environment. This approach has been questioned because it didn't take into consideration the element of freedom underlying the emergence of a civilization or a world. One conceives therefore of a civilization as a product of a response to the environment. To this view one rightly objects by saying that the various societies do not conceive of their world in that manner. What we call their environment, meaning by it the condition of their world, is for them a part of their world. Mr. Riezler has illustrated this occasionally by the example of the tin cans and the Andaman Islanders. ${ }^{5}$ The tin cans are not tin cans for the Andaman Islanders. If we want to understand the world of the Andaman Islanders we have to understand those objects which we know as tin cans, exclusively in the way in which the Andaman Islanders understand them. Still, we have to admit that we understand the situation better if we take into consideration the fact that the objects in questions are tin cans. Can we make ourselves more ignorant than we are? And if we could, why should we? Knowing that the objects are tin cans, [6] whereas the Andaman Islanders do not know it, we are forced to understand those people better than they understand themselves. We have transcended their world in order to understand their world. In the language of a famous ${ }^{6}$ philosopher, social science has to understand both how things are in themselves, and how they are for a given people: the full understanding of a society comprises both, the "in itself" and the "for them."

\footnotetext{
5“An anthropologist reports that the Andaman Islanders collect (empty) tin cans. He can be said to describe the life of the Andaman Islanders in terms of his own environment. But these are tin cans, 'objectively'; they are manufactured in Philadelphia, as tin cans. Yes, but this kind of objectivity is irrelevant. They are what they are in the environment of the Andaman Islanders - rare, round, shiny objects - by virtue of the role they play in Andaman life" (Riezler, "Some Critical Remarks," 490).

${ }^{6} \mathrm{~A}$ handwritten "famous" replaces a crossed out "[a]n earlier."
} 
An anthropologist comes to a tribe never visited before by anthropologists. By some means, he has acquired adequate knowledge of the language of the tribe before joining them. He has an open mind. By living with these people, by avoiding leading questions, he will try to find out gradually what their frame of reference is: what they consider most important or most fundamental. They may not know that there is anything which they consider most fundamental or most important; as Mr. Jourdain did not know that he was talking prose all his life, ${ }^{7}$ their frame of reference is only implicit. The mere fact that he wants to know something from them that they do not really know [they know it only implicitly] ${ }^{8}$ affects the situation. By bringing something to their attention which was not a theme for them, he alters the way in which they understand themselves. That is, he alters their world. The mere fact that he has come to them to understand their way, and not to spy on them, nor to trade with them, nor to hide among them, affects the situation. By getting a glimpse of the idea of science of the disinterested pursuit of knowledge, they cease to be the people they were.

To sum up: it is impossible to leave it at trying to understand other societies as they understand themselves. We are forced to transcend the selfunderstanding of the various societies.

We cannot understand societies other than our own with the help of our frame of reference. We cannot understand them through their frame of reference. Is there any alternative? Is there a frame of reference which is neither ours nor theirs? Only a frame of reference which does not belong to any particular society, only a natural frame of reference will do. [7] How are we to obtain such a frame of reference?

To find a way let us return to the point where we lost our way. Everything seemed all right, as long as we could leave it at our frame of reference, at our western frame of reference, which seemed to correspond to the last and richest stage of the cultural development of mankind from its beginning till now. I am referring to the scheme that is underlying the notion that the way of a people is a civilization, and that a civilization consists of art, morality, religion, economics, law, science, etc. This scheme became doubtful because we realized that it is essentially related to a peculiar civilization, and truly adequate only when applied to that particular civilization. We can state this somewhat more precisely. Our frame of reference is the outgrowth of the combination of two radically different traditions [Greek and Hebrew], ${ }^{9}$ of a peculiar combination of two peculiar ways. The question is, whether a better understanding of our frame of reference, in its peculiar character, will not liberate us from its limitations.

${ }^{7}$ This reference to Molière's Le bourgeois gentilhomme, act II, scene 4 has been added by hand.

${ }^{8}$ The square brackets are Strauss's.

${ }^{9}$ The square brackets are Strauss's. 
Our frame of reference, to repeat, is the product of a combination of two peculiar ways. Yet the two radically different ways, the Greek way and the Hebrew way, have a common basis. This common basis shows itself if we go back from the peaks to the roots: from Plato's dialogues to Lycurgus as the Spartans saw him, from Jesyah ${ }^{10}$ or Paul to Moses as the Hebrews saw him. Provisionally expressed, the common basis is the notion of a divine law, a notion that can be shown to be a necessary consequence or a more thoughtful expression of what all peoples originally mean when they speak of their way. For "our way" is the ancestral way, the way of our ancestors, but it doesn't make sense to cling to the way of our ancestors if our ancestors were not superior to us. And superiority to us ultimately means superiority to human beings as such, that is to say, divinity.

[8] The notion of divine law became questionable in the moment when man became sufficiently familiar with the variety of ancestral or divine ways, or with $^{11}$ the contradiction between these ways. Out of this experience, there arose the idea of nature and the idea of science. In the light of the ideas of nature and science the Greeks investigated the various tribes to which they had access. For these investigations they used a clear and simple scheme which is still immediately intelligible to us. At the same time that scheme is historically so close to what was originally common to all peoples that it is least likely to be based on any particular and questionable assumptions. It seems to me that we would recover the natural frame of reference by recovering the frame of reference used by the classics.

\section{Leo Strauss Papers, Box 14, Folder 9 Note on "Some critical remarks on man's science of man"12}

[1] Since man is one, there ought to be one science of man. That science would be a fundamental science, if not the fundamental science. By understanding

${ }^{10}$ Strauss has crossed out "Jo" and "Jesaya." Strauss may be referring to Joshua (of Exodus, Numbers, and Joshua) as a peak in the sense of entering the promised land as Moses's successor; another possibility is that the reference is to Jesus.

${ }^{11}$ Strauss has crossed out "between."

${ }^{12}$ Numbers in parentheses indicate pages in Riezler article cited above, note 1. A footnote marked by an " $x$ " next to the title reads (editorial insertions in brackets): "cf. Summer Course on Historicism sheet 4. cf. Landgrebe [The World as a Phenomenological Problem, 38-48] in the phenomenological journal [Philosophy and Phenomenological Research 1, no. 1 (Sept. 1940)], 47, p[aragraph] 1 etc.: the transhistorical invariants as also historicist ('Welt' [world], 'Unendlichkeit' [infinity]...) fundamentally because modern natural science is assumed (implied in idea of Verstehen [understanding] $\neq$ unverständliche Natur [unintelligible nature]) $\rightarrow$ the hidden cosmological foundation: no cosmologically relevant position." In the upper left corner: "24-26.12.1945; cf. [Aquinas], S[umma] Th[eologica] I q. 75.78 .84 princ. [beginning]." 
the one and indivisible phenomenon "Man" in its completeness, by understanding how this one phenomenon offers different "aspects," and "aspects" of different relevance and "depth," it would supply the many sciences which deal with the various "aspects" of man with a solid and no longer hypothetical basis. It would replace the prevailing Babylonian confusion which is the outcome of laissez-faire "cooperation" of the many sciences dealing with man by their veritable harmony which arises from an understanding of their master plan. Following carefully and even scrupulously the natural articulation of the one phenomenon "Man," it would "cut out" for the various special sciences their subject matter. It would make manifest which, if any, of the generally recognized special sciences deal with subject matters constituted, not by the nature of things, but by the arbitrary assumptions. It would delineate the method or methods of investigation appropriate to the subject matters of the various special sciences. While thus fulfilling the task of a true methodology, it would do more than any mere methodology could: it would liberate the mind from the inevitable scholasticism of all established sciences or pseudosciences by a bold return from words, symbols, and propositions to the green pastures of the phenomena themselves: a return which is apparently presumptuous but in truth infinitely more modest or wise than the pride of possession begotten by ever more swelling "bodies of knowledge."

[2] Riezler's suggestion holds out so great and so fair promises of a restitutio in integrum ${ }^{13}$ of the sciences dealing with man and especially of the social sciences that it is an invidious task to raise any objection to it. To avoid any misunderstanding, it must be stated at the outset that the objections which will be made here are based on full agreement with what Riezler says or implies about the present state of affairs. No attempt will be made to defend the indefensible.

Riezler's exposition creates the impression as if the absence of the one science of man which he demands were due to the emergence in the 19th century of specialized and unphilosophic sciences dealing with various "aspects" of man. Thus it does not become clear that the demand for the one ${ }^{14}$ science of man is not a self-evident demand to which every sensible man must subscribe. It does not become clear, in other words, that Riezler's demand rests on quite specific, and by no means self-evident, presuppositions.

Exactly the same reasoning that leads to the demand for the one science of man leads to the demand for one science of "the whole," for the one "first philosophy." If one is not permitted to "acquiesce in the split" between mind and body, physical and mental experience, individual and society, one is not permitted to "acquiesce in the split between man and nature." Thus as the one

\footnotetext{
${ }^{13}$ "Restoration to its integrity," a term of Roman contract law.

${ }^{14}$ Strauss has "a" instead of "the one."
} 
nature of man embraces body and mind, individual and society, physical and mental experience, "one nature embraces" both human nature and nonhuman nature (483). Our reasonable longing for unity and intelligibility cannot come to rest before we have grasped at least the need for the one universal science of nature. This need is not fulfilled by modern natural science. In the first place, modern natural science has proved to be utterly unable to do justice to the phenomenon "Man." Above all, modern natural science understands [3] nature within the framework supplied by quite specific assumptions, by assumptions that are dictated by the requirements of a specific method rather than by the nature of things itself (cf. 504). The universal science toward whose postulation Riezler's argument leads would be akin, not to modern natural science, but to the natural science of Aristotle or to that of Goethe.

The specific presupposition on which Riezler's demand for the one science of man rests is the rejection of the universal science thus understood. His reason can be stated as follows. The universal science of Aristotle or that of Goethe finds "the system of permanences" at which science necessarily aims, in a "cosmic scheme." But all "cosmic schemes" depend on something more fundamental of which they are a function; they "come to be and perish" "in the dynamic context" of human life (488). One cannot help wondering why the anthropological "schemes" - "the system of permanences" to be found "in the dynamic context" of human life-should be exempt from the fate of the "cosmic schemes": are they supposed to dwell in a "static" beyond, or to subsist out of reach of the "dynamic context"? If man's views of the cosmos necessarily change in accordance with the changes of the "dynamic context" in which he lives, his views of himself are bound to change for the same reason and at the same pace. Historicism is not a cab that one can stop at his convenience. ${ }^{15}$ On the other hand, if man, being the animal rationale, has the possibility of transcending his "historical" limitations by discovering eternal permanences residing in the structure of human life, there is no reason why he should not have the possibility also of discovering the eternal order of the cosmos. The fact that man is nearer to himself than is the cosmos, would obviously not be a sufficient reason. If ${ }^{16}$ man is essentially a part of the cosmos, if one nature embraces both human and nonhuman nature, there cannot be a true understanding of man but [4] within the framework of a lucid "cosmic scheme."

One cannot avoid this conclusion by suggesting that when rejecting "the split between man and nature," Riezler does not mean what he seems to say. It is true, a case can be made for the view that the split to which he objects is not really the split between man and nature, but the split between man and his world ("man's world"), between man and "the world in which

\footnotetext{
${ }^{15}$ See What Is Political Philosophy?, 72.

${ }^{16}$ Strauss has crossed out "For if."
} 
we live, care and act," between "the group" and "the world of things interpreted by the group" (499-502). Yet since "our world" is not "the world" (501), since our "world" depends on the world-we need the sun, but the sun does not need us and our works - one cannot avoid the question of the relation of that state in the state which is the "world" of man to the world simply of which the former is a part. One cannot understand man if one does not understand his place in the universe. Riezler himself cannot even indicate what he considers the nature of man without throwing out some hints about the nature of stones, plants, and animals (495f.).

There are perhaps people who believe that the demand for a universal science which understands man as well as minerals, plants, animals, and stars in the light of the whole, is compatible with the demand for an additional science of man which understands man and his world in the light of human life. Yet the attempt to understand man in the light of human life seems to lead to the disintegration, and the disappearance, of the very "object" of this science of man; it seems to lead to the dissolution of the oneness of man. In "the dynamic context of life," Riezler suggests, we never meet man: we always meet "this or that man or group of man" $(492,494)$. If this is so, the science of man which understands man in the light of human life would understand at most individual men, individual groups, individual societies. Nor is this all. As has been indicated before, it is difficult to see how Riezler can avoid the admission that his [5] science of man belongs itself to "the dynamic context" of human life. Since that context is always an individual context, the unity of the "subject" of the science of man would disappear as well as the unity of its "object." Philosophy would undergo a transformation into autobiography, lyrical poetry, and things like that; and the transformation would not stop there. There could be one science of man only if the "anonymous observer whose data no possible observer [of equal intelligence ${ }^{17}$ can contest" would take precedence over "any particular concrete observer" - contrary to what Riezler clearly suggests (492). A science of man which tries to understand man and his "world" in the light of "the dynamic context" of human life would seem to have to abandon at least every claim to "objectivity."

That this fear is not wholly unfounded may be seen from the following consideration. Social science however understood cannot dispense with investigations of the "worlds" of the various societies. It has to understand "all things" that are what they are "with respect to" an individual society in the sense in which they are understood, or interpreted, by that society. But one must wonder whether it can fulfill this task properly if it does not consider ${ }^{18}$ these same things also as they truly are or, as people nowadays say, "objectively." Riezler is consistent enough to say that "this kind of objectivity is

\footnotetext{
${ }^{17}$ Square brackets by Strauss.

${ }^{18}$ Strauss typed over the words "to begin" after "consider."
} 
irrelevant" (490). He illustrates his view as follows: "things that do not belong to the geographical or physical environment, may play an important role in the functional environment: spirits in trees and rivers, and the souls of the dead" (493). In a sense this is true: within certain limits exactly the same consequences follow for the life of believers in witchcraft whether there are witches or not. And yet for the scientist, and even for the social scientist, the right answer to the question as to whether there are, or are not, witches, spirits in trees and rivers, or souls of the dead, is infini-[6] tely more important than the most perfect "empathy" with those who hold such beliefs. For is it not of crucial importance for every intelligent orientation in the world that whereas trees and river[s] exist simply so that every human being can become aware of their being by sense perception, witches and spirits do not exist simply (at least as far as I can see) but owe their "being" merely to the belief of specific human groups? And is this difference not of crucial importance especially for the social scientist who in one way or another has to distinguish between higher or lower civilizations, between higher or lower beliefs? Is the idea of civilizing Riezler's Andaman ${ }^{19}$ Islanders or other savages, i.e., of replacing their "world" by another "world," a better "world," entirely absurd? To assert that the "objective" consideration of the various civilizations is irrelevant, or that only the understanding of the various civilizations from their own point of view is legitimate, may be necessary if one wants to understand human life from the point of view of human life, but it is tantamount to abandoning forever every hope of ever getting hold of criteria which would enable every sufficiently intelligent and industrious man reasonably to judge of the various civilizations, of the justice of their customs and of the truth of their beliefs. This is not to deny of course that for certain indispensable, but always subsidiary, purposes, viz., for the purposes of historical understanding, the understanding of each specific "world" in the way it which understands itself is the one thing needful.

It is merely another formulation of the same objection if one says that the science of man, as Riezler understands it, is a theoretical and not a practical science. It is guided by the intention to bring to light the "definite structure" of "all (human) life," it is not guided by the question of the right way of life. Riezler does not discuss the question as to whether human life can be understood [7] at all in its "definite structure" if it is not approached from the point of view of the question of the right way of life.

Our contention that the demand for the one science of man is not selfevident, or almost self-evident, is confirmed by a glance at the history of philosophy. If Riezler's demand were the natural outcome of every ${ }^{20}$ genuinely

\footnotetext{
${ }^{19}$ Strauss has, either typed or handwritten, both "the Andaman" and "Riezler's Andaman."

${ }^{20}$ Strauss has crossed out "any."
} 
philosophic preoccupation with the problem of man, the history of philosophy might be expected to abound with records of philosophers who engaged in the quest for such a science. That demand is particularly appealing to our age; but this has no reason other than the fact that the "idealistic" orientation of modern philosophy is lingering on beyond the breakdown of idealistic philosophy proper: the view that "man is the substance" is the natural offspring of the Hegelian view that "the subject is the substance"21 (cf. Riezler's identification of "subject" with "being in itself": 496); "man" as understood by present-day philosophic anthropology is the heir to ${ }^{22}$ the "mind" or "consciousness" of earlier generations of modern philosophers. "We are still under the spell of prejudices which originated in the Renaissance," as Husserl said. ${ }^{23}$ Classical philosophy had no place for the one science of man: it split up the study of man among theoretical and practical philosophy, or among logic, physics, and ethics. The classical division of philosophy or science remained the beacon of philosophic orientation until a relatively short time ago. This led to the consequence that the splitting up of the study of man among a number of distinct disciplines is still generally taken for granted. It explains also why the history of philosophy has very little to tell about the one science of man. Among the philosophers who demanded such a science, none is more memorable than Bacon. Bacon made a distinction between "natural philosophy" and "human philosophy." This distinction cannot be mistaken for the Aristotelian distinction between natural philosophy and [8] philosophy concerning human things; for according to Aristotle, the study of human nature is a part of natural philosophy, whereas according to Bacon that study is a part of human philosophy; to say nothing of the fact that the Aristotelian distinction is equivalent to the distinction between theoretical and practical philosophy, whereas for Bacon the distinction between theoretical and practical philosophy ceases to be fundamental. Bacon was fully aware of both the fact that, and the reason why, he opposed the classical tradition by his demand for the one science of man. He says: "the works of God ... do show the omnipotency and wisdom of the Maker, but not His image: and therefore therein the heathen opinion differeth from the sacred truth, for they supposed the world to be the image of God, and man to be an exact or compendious image of the world, but that Scripture never vouchsafe to attribute to the world that honour, as to be the image of God, but only the work of His hands: neither do they speak of

\footnotetext{
${ }^{21}$ E.g., Phenomenology of Spirit, Preface, sections 1 and 25; "Absolute Knowledge," section 803.

${ }^{22}$ The word "to" is repeated.

${ }^{23}$ Perhaps a reference to Edmund Husserl, The Crisis of the European Sciences and Transcendental Phenomenology (Evanston, IL: Northwestern University Press, 1970), Part I, section 3.
} 
any other image of God, but man."24 The idea of one science of man which deals with both human nature and the human things thus seems to be based ultimately on the Biblical view of man.

To understand the fact that the philosophic tradition split up the study of man among two main branches of inquiry-among the study of human nature which was considered a part of natural science, and the study of human things which was practically identical with political philosophy in the broad sense of the term-it suffices perhaps to understand a passage of the Nicomachean Ethics (1141a22-24). Aristotle says: "healthy' and 'good' are different when applied to men or to fish, but 'white' and straight' are the [9] same always." If we call something healthy or good, we imply that it is healthy or good for man. But if we say that a body ${ }^{25}$ is white or that a line is straight, we do not imply that the body is white for man only or that the line is straight for man only. There are things that are what they are simply and there are things that are what they are only for man as man, to say nothing of other things that are what they are only for man belonging to specific groups. This fundamental distinction is at the bottom of the distinction between theoretical and practical philosophy, and in particular of the distinction between the study of human nature and the study of human things, i.e., of the things that are what they are only for man. It is interesting to observe how Riezler uses this fundamental distinction. He identifies it with the distinction between "subjects" and "objects": "subjects" have absolute being, whereas "objects" have only a relative being. For "objects" "are of use or of no use, good or bad, healthy or poisonous to somebody." A stone, e.g., is an "object." This means that "the stone is something to be thrown, to stumble over, to be used for a house" (496). The difficulty is that the stone could not have this "functional" significance if it did not have a specific being of its own in the first place, and that is that specific being of its own, and not its "functional" significance, which makes a stone a stone. One cannot help being struck by the kinship of this anthropocentric interpretation of at least inorganic nature with the interpretation given in Genesis, of sun, moon, and stars as lights to divide the day from the night and things which are "for signs, and for seasons, and for days, and for years." Is then Riezler also ${ }^{26}$ among those who expect the restoration of philosophy from a return to theological notions?

24“'See Advancement of Learning, Everyman's Library ed., pp. 85, 88, and 94 [Book II, chap. 6, par. 1]. Cf. also the plan of Hobbes's De homine. Cf. on the other hand Thomas Aquinas's Summa Theologica I-II, Prologue ['Since, as Damascene states (De Fide Orthod. ii. 12), man is said to be made to God's image, in so far as the image implies an intelligent being endowed with free will and self-movement: now that we have treated of the exemplar, i.e., God, and of those things which came forth from the power of God in accordance with His will; it remains for us to treat of His image, i.e., man, inasmuch as he too is the principle of his actions, as having free will and control of his actions']."

${ }^{25}$ Strauss previously had "color" for this and the next occurrence of "body."

${ }^{26}$ The words that follow are handwritten. 